\title{
An Assessment of the Nutritional Knowledge, Practice and Status of Adult HIV/Aids Patients Attending an Art Centre in Jos, North Central Nigeria
}

Banwat ME*, Yakubu NW, Olalude EO and Ogunsakin JA

Department of Community Health, Faculty of Medical Sciences, University of Jos, Plateau State, Nigeria

\begin{abstract}
Background: The intimately multidirectional relationship between nutrition and HIVIAIDS has been established. Although adequate nutrition can neither cure nor prevent the infection, it plays a major role in the maintenance and improvement of the immunological status of PLWHA thus delaying disease progression and improving patients' quality of life. This study aimed at assessing the factors affecting knowledge and practice of adequate nutrition among adult HIVIAIDS patients attending an AIDS Out-Patient clinic in Jos, North-Central Nigeria.
\end{abstract}

Methodology: This was a cross-sectional descriptive study where 250 patients on treatment in APIN Clinic were selected using systematic sampling technique. Structured interviewer-administered questionnaires were used to gather data from them which were collated and analyzed using EPI info version 3.5.3 Statistical software. Chi-square statistical test was used to assess association and a p-value of less than or equal to 0.05 was considered to be statistically significant.

Results: Majority of the respondents $(55.9 \%)$ felt protein was the most important food nutrient in their diet. Many of the respondents $(48 \%)$ reported spending up to $25-50 \%$ of their monthly income to ensure they have adequate nutrition. A small proportion of the respondents $(22.9 \%)$ reported early satiety as the main factors affecting their daily dietary intake while the cost of a food item was the major hindrance to ingesting a preferred food group. Forty five percent of the respondents reported fruits and vegetables as the major components of their daily diet. There was a statistically significant relationship between the BMI of the respondents and the duration on ART prior to the study.

Conclusion: The knowledge and practice of adequate nutritional intake was fairly good among studied HIV/ AIDS patients. It however needs to be improved through more involvement of health workers, the media, as well as governmental and non-governmental organizations in nutrition education and poverty alleviation.

\section{Keywords: Nutrition; Nutritional knowlwdge; HIV/AIDS}

\section{Introduction}

Human Immune-deficiency Virus (HIV) infection and Acquired Immune Deficiency Syndrome (AIDS) are caused by the Human Immune-deficiency Virus which has various serotypes. Since the isolation of the first confirmed case of the disease in 1981, HIV/AIDS has become a global health problem, with the bulk of the disease borne by Sub-Saharan Africa [1]. Many HIV-related conditions affect and are affected by the body's nutritional status [2].

HIV and nutrition are interrelated and as antiretroviral drug become increasingly available in the poorest parts of the world, critical questions are emerging about how well the drugs work in people if they are short of food, and for those already receiving treatment, side effects such as body fat changes are a daily concern [2,3]. Maintaining a good nutritional status is important to support the overall health and immune function of people living with HIV/AIDS (PLWHA). Adequate nutrition refers to intake of a diet which meets the specific nutritional needs for the specific individual for that specific period in time [3]. The sole aim of adequate nutrition is to meet the growth and developmental demands of the unique, specific individuals' body [4]. Inadequate nutrition in people with HIV infection may result from many factors including nausea, vomiting and anorexia that may prevent adequate intake of nutrients and medications; diarrheal infections that prevent absorption of nutrients and medications; Oral health conditions that interfere with chewing or tasting food like Oral Candidiasis in patients who present late; systemic illness (including HIV itself) that create a catabolic state; and psychological conditions such as depression that impair patients' ability to nourish themselves [3,5]. In addition, financial constraints may limit patients' access to nutritious food [4].

Adequate nutrition helps to maintain and improve the nutritional and immunological status of a person with HIV/AIDS and delay the progression from HIV to AIDS-related diseases [5]. It can therefore improve the quality of life of PLWHA. Adequate nutrition will complement the effects of antiretroviral therapies and will help to maintain body weight and fitness, as well as improve the performance of the immune system already compromised by the infection [5]. Whereas starving people tend to lose fat first, the weight lost during HIV infection tends to be in the form of lean tissue such as muscle mass; this has been attributed to ARTs like Polymerase Inhibitors. This means there may be changes in the makeup of the body even if the overall weight stays the same [6,7]. One factor behind HIV-related weight loss is increased energy expenditure $[8,9]$. Many studies indicate that people with HIV tend to burn around $10 \%$ more calories while resting, compared to those who are uninfected [6-9]. Nutritional control of weight can be effectively used to balance out these body changes in infected patients.

Current antiretroviral drug treatments control HIV infection and prevent severe wasting, as well as other AIDS - related conditions. Emaciated persons tend to regain weight once they begin antiretroviral

*Corresponding author: $\operatorname{Dr}$ (Mrs.) Mathilda E Banwat, Department of Community Health, Faculty of Medical Sciences, University Of Jos, Plateau State, Nigeria, Tel: 234-8036133983; E-mail: mathildabanwat@yahoo.com

Received July 23, 2013; Accepted August 24, 2013; Published August 26, 2013

Citation: Banwat ME, Yakubu NW, Olalude EO, Ogunsakin JA (2013) An Assessment of the Nutritional Knowledge, Practice and Status of Adult HIVIAids Patients Attending an Art Centre in Jos, North Central Nigeria. Health Care Current Reviews 1: 101. doi: 10.4172/2375-4273.1000101

Copyright: (c) 2013 Banwat ME, et al. This is an open-access article distributed under the terms of the Creative Commons Attribution License, which permits unrestricted use, distribution, and reproduction in any medium, provided the original author and source are credited. 
therapy and stunted children experience catch-up growth [8]; however the drugs do not eliminate wasting. In addition, some antiretroviral drugs have been linked to lipo-dystrophy, as well as lipid abnormalities by raising Low Density Lipoprotein (LDL) cholesterol, lowering High Density Lipoprotein (HDL) cholesterol and raising triglyceride levels in the blood $[9,10]$. This may result in higher risks of heart disease, Cerebro-Vascular Accidents (CVA) and diabetes mellitus [10]. One study in Malawi found that patients with mild malnutrition (a Body Mass Index (BMI) of $17.00-18.49 \mathrm{~kg} / \mathrm{m}^{2}$ ) were twice likely to die in the first three months of treatment; and for those with severe malnutrition (BMI less than $16.00 \mathrm{~kg} / \mathrm{m}^{2}$ ), the risk was six times greater than those of healthy body weight (BMI ranging between $18.5-24.99 \mathrm{~kg} / \mathrm{m}^{2}$ ) [11].

Since the beginning of the pandemic, over 30 million people have died from AIDS-related causes globally [12]. In Nigeria, an estimated $4.6 \%$ of the populations are living with HIV/AIDS [13]. Although HIV prevalence is much lower in Nigeria than in other African countries the enormous size of Nigeria's population makes this prevalence to be a large number. The HIV pandemic has also significantly compromised the food security of affected households and communities, reducing the availability of productive labor, diverting income, depleting savings and productive assets and impeding intergenerational knowledge transfer [14]. In some contexts, food insecurity may lead to more migratory livelihood strategies and high-risk sexual behaviors that increase the risk of HIV transmission [13,14].

The study area (Jos, North-Central Nigeria) in recent times, has witnessed a lot of civil unrest and ethno-religious crises which have further adversely affected food security and availability, hence posing as a constraint to adequate nutrition. With the relatively increased prevalence of HIV/AIDS in Plateau state (at about $7.7 \%$ by 2010), as well as in other neighboring regions, the population of patients seen at APIN centre has increased drastically to more than 1000 adults per week [13]. This study aimed at assessing the factors affecting knowledge and practice of adequate nutrition among adult HIV/AIDS patients attending an AIDS Out-Patient clinic in Jos, North-Central Nigeria.

\section{Methods and Materials}

\section{Study area}

The study was conducted in the AIDS Prevention Initiative in Nigeria (APIN) centre within Jos University Teaching Hospital (JUTH) in Jos, Plateau State, North-Central Nigeria. APIN is a Public-Private Partnership funded organization, which is involved in the provision of HIV/AIDS prevention, treatment and care services. Other services it renders include: Prevention of mother to child transmission (PMTCT) of HIV, Paediatric HIV care and treatment, Tuberculosis/HIV care and treatment, Laboratory infrastructure procurement and supply and Training and human resource capacity building.

APIN centre is located in Jos North Local Government Area (LGA) of Plateau State, North-Central Nigeria, within the temporary site of the Jos University Teaching Hospital (JUTH).

\section{Study design}

This was a cross-sectional, descriptive study, to assess the knowledge and practice of adequate nutrition among HIV/AIDS patients in APIN Centre, Jos.

\section{Study population}

The majority of patients at APIN centre come from within Plateau state, with a significant number also coming from neighboring states within the North-Central part of Nigeria including Benue, Kaduna and Nassarawa states. The bulk of patients at APIN centre are adult HIV patients although a significant number of children also attend the paediatric clinics. The social status of patients at APIN centre cut across all social strata with most of the adults being literate and employed in professional, skilled and manual labor; A Professional occupation has an approved standard curriculum of training for students in institutions (Lawyer, Medical doctor, Nurse), a skilled profession needs a period of skill acquisition as an apprentice under an instructor but has no curriculum for training (Tailor, Welder, Motor mechanic) while a manual laborer needs no specific period under an instructor to be in the trade (a Night watchman, farmer, petty trader).

\section{Inclusion/Exclusion criteria}

The target population of the study comprised of adult patients (18years and above) attending APIN centre for at least three months prior to the study; all subjects were either on ART or had been on ART within the past 12 months of the study. Patients less than 18 years of age and over 65 years, indigent patient, as well as those registered in the APIN clinic, less than three months prior to the study were excluded from the study. The elderly (aged above 65 years) excluded from the study since aging on its own is a predisposing factor for malnutrition and could act as a confounder. The use of BMI to assess nutritional status is also unreliable due to skeletal deformities with age which affect height (Table 1).

\section{Sample size determination}

A minimum sample size was determined using the formula: $N=\frac{Z^{2} p q}{d^{2}}$

\begin{tabular}{|c|c|c|}
\hline Variable & Frequency $(\mathrm{N}=\mathbf{2 5 0})$ & Percentage \\
\hline \multicolumn{3}{|l|}{ Age(Years) } \\
\hline $18-29$ & 39 & 15.6 \\
\hline $30-39$ & 111 & 44.4 \\
\hline $40-49$ & 74 & 29.6 \\
\hline $50-59$ & 26 & 10.4 \\
\hline \multicolumn{3}{|l|}{ SEX } \\
\hline Males & 118 & 47.2 \\
\hline Females & 132 & 52.8 \\
\hline \multicolumn{3}{|c|}{ Highest Educational Status Attained } \\
\hline None & 5 & 2.0 \\
\hline Primary & 23 & 9.2 \\
\hline Secondary & 90 & 36.0 \\
\hline Tertiary & 132 & 52.8 \\
\hline \multicolumn{3}{|l|}{ Occupation } \\
\hline Students & 40 & 16.0 \\
\hline Professional & 61 & 24.4 \\
\hline Skilled worker & 78 & 31.2 \\
\hline Unskilled worker & 36 & 14.4 \\
\hline Unemployed & 35 & 14.0 \\
\hline \multicolumn{3}{|l|}{ Marital Status } \\
\hline Single & 66 & 26.4 \\
\hline Married & 137 & 54.8 \\
\hline Divorced & 10 & 4.0 \\
\hline Separated & 3 & 1.2 \\
\hline Widow/Widower & 34 & 13.6 \\
\hline
\end{tabular}

Table 1: Socio-Demographics of the Respondents.

There was a non-response rate of $2.8 \%$. The mean age of respondents was 37.8 \pm 8.9 years with the median duration on ART being 4 .38years. The highest proportion of respondents were aged between 30 and 39 years $(44.4 \%)$, female $(52.8 \%)$ skilled workers (31.2\%) and married $54.8 \%$ ). 
Where:

$\mathrm{N}=$ Minimum sample size

$\mathrm{Z}=$ Standard deviation at $95 \%$ confidence interval $=1.96$

$\mathrm{p}=$ Anticipated proportion/population of PLWHA with appropriate knowledge and practice of adequate nutrition $=20.9 \%(0.209)$ from a similar survey [15].

$\mathrm{q}=$ Complementary probability $=1-\mathrm{p}$

$$
\begin{aligned}
& =1-0.209 \\
& =0.791
\end{aligned}
$$

$\mathrm{d}=$ Error margin $/$ tolerance $=5 \%=0.05$

Hence:

$$
\begin{aligned}
N & =\frac{(1.96)^{2} * 0.209 * 0.791}{(0.05)^{2}} \\
N & =\frac{0.6351}{0.0025}=244.04 \\
\mathrm{~N} & =250
\end{aligned}
$$

The minimum sample size was therefore 250 patients.

\section{Sampling technique}

The sampling method used was systematic sampling; of the equal - probability modality. This sampling interval was elucidated using the formula:

$$
K=\frac{N}{n}
$$

Where:

$\mathrm{K}$ = sampling interval by which every Kth element/subject was selected from the sampling frame.

$$
\begin{aligned}
& \mathrm{N}=\text { population size of patients }=1000 \times 2=2000 \text { (in four weeks) } \\
& \mathrm{n}=\text { sample size }=250 \text { patients } \\
& K=\frac{2000}{250}=8 \\
& \text { Hence }
\end{aligned}
$$

Therefore, within 4 weeks of sampling, every $8^{\text {th }}$ patient was selected from the entire sampling frame of 2000 patients to comprise the 250 patients as sample size, given the logical homogeneous composition of the population.

\section{Instruments for data collection}

Data was collected by interview-administered structured questionnaires which was framed by the researcher from the objective of the research and was up of five sections:

Section A: assessed the Socio-demographic data of the patients

Section B: Assessment of knowledge of adequate nutrition

Section C: Assessment of practice of adequate nutrition

Section D: Assessment of the determinants and deterrents to adequate nutrition.

Section E: Others - including nutritional assessment by anthropometric measurements.
Weighting scales and meter rules were used to obtain weights (in kilograms) and heights (in meters) of subjects respectively, using standard procedure: Subjects were weighed twice with minimal clothing and the average of the reading recorded while they stood against a wall with their heel, buttocks and vortex against the wall for their heights to be measured in meters. Their BMI was then calculated (Weight in kilograms/Height in meters ${ }^{2}$ ) and recorded.

\section{Data analysis}

Data collected was collated and analyzed using EPI info version 3.5.3 Statistical software. Significant relationship between BMI of respondents and the duration of HAART was evaluated using Chisquared $\left(\chi^{2}\right)$ test. The $p$ value of $\leq 0.05$ was taken as statistically significant.

\section{Ethical considerations}

Ethical approval for the study was given by the Research and Ethics Committee of the Jos University Teaching Hospital (JUTH). A letter of approval was also obtained from APIN centre to conduct the study. A letter of identification from the Department of Community Health was given to the research team. Prior to administration of the questionnaires, written informed consent was obtained from each patient after being assured of the confidentiality of volunteered information. Incentives to the participants included free nutritional counseling and education on the research topic.

\section{Limitations to the study}

The nature of the study, being a "snapshot" of the nutritional characteristics of the patients, hindered any prospective/follow-up activities with appropriate documentation.

Recall bias remains a limitation since the subjects had to remember components of their nutritional intake as well as other discrete pieces of information.

\section{Discussion}

A good knowledge of nutritional requirements for an individual with a chronic disease has been found to be vital for proper management of the disease as well as prevention of complications [16-18]. Majority of the respondents $(55.9 \%)$ in this study considered protein to be the most important food nutrient they need to ensure an adequate diet and to ensure they stay strong despite their diseased state (Table 2). This suggests that a good proportion of them have an understanding of the fact that HIV/AIDS is an immune deficiency disease and the role of protein in the production and functioning of the immune system. This perception was further strengthened by majority of them giving the principal reasons for placing priority on that particular food nutrients included its function in building and strengthening of the immune system and improvement of health. A study in Anambra state of Nigeria, among pregnant women also showed an above-average knowledge score regarding food classes required in pregnancy and the usefulness of protein in ensuring a healthy mother and baby at the end of pregnancy [19]. Nutrition guidelines for HIV/AIDS patients explains the importance of protein in building muscles, organs and a strong immune system $[16,18]$. Furthermore nutritional counseling given to HIV/AIDS patients in clinics (like the study area) provides the needed information on the importance of food nutrients.

In this study, most of the participants reported an increase in cost and geographical inaccessibility of food items as the major constraints to adequate dietary intake in terms of quantity and quality of meals 
Citation: Banwat ME, Yakubu NW, Olalude EO, Ogunsakin JA (2013) An Assessment of the Nutritional Knowledge, Practice and Status of Adult HIV/ Aids Patients Attending an Art Centre in Jos, North Central Nigeria. Health Care Current Reviews 1: 101. doi: 10.4172/2375-4273.1000101

Page 4 of 5

\begin{tabular}{|c|c|c|}
\hline Variable & Frequency $(\mathrm{N}=250)$ & Percentage \\
\hline \multicolumn{3}{|c|}{ Most Important Food Nutrient } \\
\hline PROTEINS & 117 & 46.8 \\
\hline MINERALS/VITAMINS & 66 & 26.4 \\
\hline CARBOHYDRATES & 13 & 5.2 \\
\hline FATS/OILS & 7 & 2.8 \\
\hline WATER & 6 & 2.4 \\
\hline DON'T KNOW & 41 & 16.4 \\
\hline \multicolumn{3}{|c|}{ Reason for Choice of Nutrients } \\
\hline It builds immunity & 114 & 45.6 \\
\hline It improves wellbeing & 29 & 11.6 \\
\hline It provides energy & 25 & 10.0 \\
\hline It helps drugs work well & 21 & 8.4 \\
\hline It enables weight gain & 14 & 5.6 \\
\hline Others* & 47 & 18.8 \\
\hline
\end{tabular}

Others $^{*}=$ Cleanses the body, repairs damages made by disease, no reason given

Table 2: Perception of the Most Vital Food Nutrient in Their Diet

Majority of the respondents $(55.9 \%)$ felt protein was the most important food nutrient in their diet while only $2.9 \%$ felt water was the most important. Majority of the respondents $(54.5 \%)$ cited building the immune system as the reason for their consideration of a food nutrient as important while only $6.8 \%$ felt it helped them look good.

ingested (Table 3). This could be associated to the crises in Jos which make food cultivation and transportation difficult and expensive. This is in consonance with a study by Nelson in Delta State, Nigeria where inadequate funds and location of markets were major determinants of food items ingested by the studied population [20]. It is however slightly different from findings among studied pregnant women in Imo state of Nigeria, where cultural factors like food taboos were a major constraint to ingestion of certain food items; as well as cost [19]. The uniformity of cost as a constraint in these and many other studies may be attributed to the general dire economic and financial constraints experienced nationally and globally with its attendant inflation of food prices. It can also be explain by the fact that the respondents in this study who are majorly workers have a restricted schedule and apportioned time for eating with limited choices of food varieties during working hours.

In this study, a large proportion of respondents spend between $25-50 \%$ of their monthly income on nutrition (Table 4 ). This finding is similar to that calculated by the United States Development Agency for Nigeria of $40.1 \%$ [21]. It is also comparable to that of other developing countries; Cameroon (38.5\%), India (35.8\%), China (33.9\%) but far higher than findings in developed countries like United Kingdom (8.9\%), United States of America (6.8\%) and Canada (9.1\%) [21]. This difference between developing and developed economies can be explained by the poverty in developing countries which means the meager income in most homes is used to meet basic physiological needs. It can also result from the fact that an average Nigerian family size is larger than what is found in developed countries; this increases the proportion of income required to meet nutritional needs [22].

Approximately $53 \%$ of the respondents (using Body Mass Index, BMI), were of normal weight, $30 \%$ overweight and $14.4 \%$ obese; with only $2.8 \%$ being underweight (Table 5 ). There was a statistically significant relationship noted between BMI and duration of commencement of antiretroviral therapy (ART). This association may be explained by the ability of the drugs to decrease resting-energy expenditure in the respondents which is reportedly about $10 \%$ and $20 \%$ higher in asymptomatic and symptomatic HIV patients respectively $[21,23]$. The drugs help to decrease the basal metabolic rate commonly

\begin{tabular}{|c|c|c|}
\hline Variable & Frequency $(\mathrm{N}=250)$ & Percentage \\
\hline \multicolumn{3}{|l|}{ Factors Affecting Quantity of Meal } \\
\hline Early Satiety & 48 & 22.9 \\
\hline Depression/ stress & 45 & 21.4 \\
\hline Adverse effect of drugs & 25 & 11.9 \\
\hline Diarrhea & 18 & 8.6 \\
\hline Constipation & 17 & 8.1 \\
\hline Difficulty coordinating meals with drugs & 15 & 7.1 \\
\hline Heart burn & 12 & 5.7 \\
\hline Nausea/vomiting & 10 & 4.7 \\
\hline Pain on swallowing & 7 & 3.3 \\
\hline Use of supplements & 7 & 3.3 \\
\hline Difficulty with swallowing & 6 & 2.9 \\
\hline \multicolumn{3}{|l|}{ Factors Affecting Quality of Meal } \\
\hline Availability of food items & 45 & 18.0 \\
\hline Geographical access & 53 & 21.2 \\
\hline Cost of food items & 99 & 39.6 \\
\hline Seasonality of food items & 49 & 19.6 \\
\hline Social issues & 14 & 5.6 \\
\hline None given & 38 & 15.2 \\
\hline \multicolumn{3}{|l|}{ Major Component of Daily Diet } \\
\hline Cereals & 68 & 27.2 \\
\hline Meat/Fish/Milk/Legumes & 65 & 26.0 \\
\hline Fruits Negetables & 114 & 45.6 \\
\hline Fats/Oils & 3 & 1.2 \\
\hline
\end{tabular}

Table 3: Factors Affecting Dietary Intake.

About $23 \%$ of the respondents reported early satiety as the main factors affecting their daily dietary intake while the cost of a food item was the major hindrance to ingesting a food item even if a respondent wanted to eat it. Forty five percent of the respondents reported fruits and vegetables as the major components of their daily diet. Only $1.6 \%$ reported eating a lot of fatty and oily foods.

\begin{tabular}{|l|l|l|}
\hline Proportion of & Frequency $(\mathrm{n}=250)$ & Percentage \\
\hline Monthly income $(\%)$ & & \\
\hline$<25$ & 41 & 16.4 \\
\hline $25-50$ & 120 & 48.0 \\
\hline $51-75$ & 68 & 27.2 \\
\hline$>75$ & 21 & 9.4 \\
\hline TOTAL & 250 & 100 \\
\hline
\end{tabular}

Table 4: Proportion of Monthly Income Spent on Nutrition.

Many of the respondents (48\%) reported spending up to $25-50 \%$ of their monthly income to ensure they have adequate nutrition.

\begin{tabular}{|c|c|c|c|c|c|}
\hline \multicolumn{7}{|c|}{ Duration of HAART (Years) } \\
\hline & $<\mathbf{1}$ & $\mathbf{1 - 5}$ & $\mathbf{6 - 1 0}$ & $>\mathbf{1 0}$ & Total \\
\hline & Freq (\%) & Freq (\%) & Freq (\%) & Freq (\%) & Freq (\%) \\
\hline$<18.5$ (Underweight) & $2(3.6)$ & $1(1.1)$ & $3(4.4)$ & $1(3.1)$ & $7(2.8)$ \\
\hline $\begin{array}{c}18.5-24.9(\text { Normal } \\
\text { weight) }\end{array}$ & $31(55.4)$ & $60(63.8)$ & $26(38.2)$ & $15(46.8)$ & $132(52.8)$ \\
\hline $25.0-29.9$ (Overweight) & $15(26.8)$ & $20(21.3)$ & $29(42.6)$ & $11(34.4)$ & $75(30.0)$ \\
\hline $30.0-39.9$ (Obesity) & $7(12.5)$ & $12(12.7)$ & $10(14.8)$ & $5(15.7)$ & $34(13.6)$ \\
\hline$>40.0$ (Morbid obesity) & $1(1.7)$ & $1(1.1)$ & 0 & 0 & $2(0.8)$ \\
\hline TOTAL & $\mathbf{5 6}$ & $\mathbf{9 4}$ & $\mathbf{6 8}$ & $\mathbf{3 2}$ & $\mathbf{2 5 0}$ \\
\hline
\end{tabular}

$X^{2}=15.18 ; d f=12 ; P=0.0231$

Table 5: Relationship between Body Mass Index (Bmi) and Duration of Using Antiretroviral Therapy (Art)

There was a statistically significant relationship between the BMI of the respondents and the duration since commencement of ART prior to the study.

responsible for weight loss, thus contributing to replenishment of muscle bulk that translates to attaining normal or even overweight. A similar relationship between progression to Obesity and duration of ART was reported among Brazilian HIV/AIDS patients [24]. 
Citation: Banwat ME, Yakubu NW, Olalude EO, Ogunsakin JA (2013) An Assessment of the Nutritional Knowledge, Practice and Status of Adult HIV/ Aids Patients Attending an Art Centre in Jos, North Central Nigeria. Health Care Current Reviews 1: 101. doi: 10.4172/2375-4273.1000101

Page 5 of 5

\section{Conclusion and Recommendations}

It was concluded from this study that knowledge of adequate nutrition was fairly good among the studied APIN patients. Most of the respondents had good practices of adequate nutrition. The major factors found to affect dietary intake of required food items was cost of the foodstuff and accessibility (geographical and seasonal). There was also a statistically significant relationship between body mass index $\mathrm{BMI}$ and duration of usage of antiretroviral therapy $(\mathrm{P}=0.0231)$.

\section{References}

1. The Joint United Nations Programme on HIVIAIDS (UNAIDS) (2009) Report on the global HIVIAIDS pandemic.

2. Bartlett JG (2003) Introduction: Integrating nutrition therapy into medical management of Human Immunodeficiency Virus. Clin Infect Dis 36: s51.

3. Association of Nutrition Services Agencies (ANSA) ANSA Nutrition guidelines and fact sheets.

4. Walsh C, Dannhauser A, Joubert G (2003) Impact of a nutrition education programme on nutrition knowledge and dietary practices of lower socioeconomic communities in the Northern Cape. South African Journal of Clinical Nutrition 16: 89-95.

5. Steinhart CR (2011) HIV - associated wasting in the era of Highly Active Antiretroviral Therapy (HAART): A Practice - based approach to diagnosis and treatment. AIDS Read 11: 557-567.

6. World Health Organization (2005) Consultation on Nutrition and HIVIAIDS in Africa: Evidence lessons and recommendations for action.

7. World Health Organization (2008) African Regional report.

8. Newell ML, Borja MC, Peckham C, European Collaborative Study (2003) Height, weight and growth in children born to mothers with HIV-1 infection in Europe. Pediatrics 3: 81-83

9. Batterham MJ (2005) Investigating heterogeneity in studies of resting energy expenditure in persons with HIVIAIDS: a meta-analysis. Am J Clin Nutr 81 92-94.

10. Sabin CA, Worm SW, Weber R, Reiss P, El-Sadr W (2008) Use of nucleoside reverse transcriptase inhibitors and risk of myocardial infarction in HIV infected patients enrolled in the D. A. D. study: Multi - cohort collaboration.
Lancet 371: 1417-1426.

11. Paton $\mathrm{NI}$ (2006) The impact of malnutrition in survival and the CD4 count response in HIV-infection, Starting antiretroviral therapy (July 2006). HIV Medicine 7: 513-515.

12. The Joint United Nations Programme on HIVIAIDS (UNAIDS) (2010) Report on the Global HIVIAIDS pandemic.

13. The United Nations General Assembly Special Session Country Progress report: Nigeria (2010).

14. United Nations Development Programme (2007) Human and income poverty: developing countries, Chapter 3: Human Development Reports.

15. Tang AU (1993) Dietary micronutrient intake and risk of progression to Acquired immune Deficiency syndrome (AIDS) in HIV type 1 infected homosexual man. American Journal of Epidemiology 138: 937-941.

16. World Health Organization (2006) Consultation on Nutrition and HIVIAIDS in Africa: Evidence, lessons and recommendation for action.

17. No authors listed (2011) Tanzania AIDS Management Training Programme, Journal of Society for women and AIDS in Dar es Salaam.

18. Erica C. Barriers to equitable access to quality health information. Journal of Medicine 5: 117-123.

19. Ihekoronye CN, Ibekanjo CU (2011) Nutritional Knowledge and Beliefs of Pregnant women in Aboh-Mbaise LGA of Imo State. Nigerian Journal of Nutritional Sciences 31: 36-39.

20. Nelson E (2010) Access to health information by people living with HIVIAIDS in Nigeria.

21. Maia-Leite LH, Mattias-Mannho-Sampaio AB (2010) Progression to Overweight Obesity and associated factors after ART initiation among Brazilian Persons with HIVIAIDS. Nutr Hosp 25: 635-640.

22. Adebayo OO (2012) Family income among small scale farmers; a panacea for household security in Oyo state, Nigeria. Research in Humanities and Social Sciences 2: 32-36

23. Tapam N, Gatongi P, Rotich J, Kimaiyo S (2008) Factors affecting antiretroviral drug adherence among HIVIAIDS patients at Moi teaching and referral hospital, Eldoret Kenya. East Af J Public Health 5: 74-78.

24. United States Development Agency/Economic Research Service (2012) Annual Income Spent on Food. 